\title{
Quantitative estimation of AgNORs in normal, dysplastic and malignant oral mucosa
}

\author{
Aman Chowdhrya, Revati Shailesh Deshmukh ${ }^{b}$, Deepika Shukla ${ }^{a}$, Deepika Bablania, Shashwat Mishrac
}

\begin{abstract}
Aims. Silver stainable nucleolar organizer regions (AgNORs) have received a great deal of attention recently as their frequency within the nuclei is significantly higher in malignant cells than in normal, reactive or benign neoplastic cells. The objective of this study was to carry out a quantitative assessment of large and small AgNORs in oral normal mucosa, precancerous lesions and infiltrating squamous cell carcinomas.

Methods. The study comprised 110 formalin-fixed, paraffin-embedded oral mucosal biopsies consisting of 30 oral dysplasia, 60 oral squamous cell carcinomas and 20 normal oral mucosa. AgNORs were counted in each nucleus, categorized as small, large and total number of AgNORs in each cell and their means were calculated.

Results. The mean value of small AgNORs, large AgNORs and total AgNORs increased gradually from normal mucosa to dysplastic lesions to squamous cell carcinomas. The study clearly indicates that in oral squamous cell carcinomas, AgNORs diminish in size as they increase in number. Further, AgNOR counts increase as the degree of malignant potential of the cell increases.

Conclusions. By combining both the enumeration of AgNORs and their size, good distinction can be made between normal, dysplastic and infiltrating squamous cell carcinomas. This could help in the early diagnosis and prognosis of dysplastic mucosal lesions and their malignant transformation.
\end{abstract}

Key words: silver stainable nucleolar organizer regions (AgNORs), oral dysplasia, squamous cell carcinomas

Received: January 22, 2012; Accepted with revision: January 8, 2013; Available online: February 13, 2013

http://dx.doi.org/10.5507/bp.2013.002

${ }^{a}$ Department of Oral and Maxillofacial Pathology and Microbiology, Faculty of Dentistry, Jamia Millia Islamia University, Maulana Mohammad Ali Johar Marg, New Delhi, India

${ }^{b}$ Department of Oral and Maxillofacial Pathology and Microbiology, Bharati Vidyapeeth Deemed University, Dental College and Hospital, Pune, India

'Department of Neurosurgery, Ram Manohar Lohia Institute of Medical Sciences, Lucknow, India

Corresponding author:Deepika Shukla,e-mail:deepika_shukla06@yahoo.com

\section{INTRODUCTION}

Millions of new cases of invasive cancer are diagnosed each year of which oral cancer has a considerably high incidence. This high incidence of oral cancer and its attendant morbidity and mortality has instigated workers to devise methods for its early diagnosis. Nucleolar organizer regions (NORs) are segments of chromosomes encrypted for ribosomal RNA (rRNA) which are present on specific loops of DNA (ref. ${ }^{1}$ ). NORs have received a great deal of attention recently because of the observations that their frequency within the nuclei is significantly higher in malignant cells than in normal, reactive or benign neoplastic cells ${ }^{2,3}$. Consequently, they are of diagnostic value for in characterization of the invasiveness in carcinomas ${ }^{4}$. They also play a role in the estimation of the cellular activity that is applied to a variety of neoplastic or hyperplastic lesions ${ }^{5,6}$. Since some of the NOR associated proteins are argyrophilic and can be demonstrated as black dots by a silver staining technique, such demonstrated structures are known as AgNORs (ref. ${ }^{4}$ ). The exact biochemical nature of these proteins is yet to be defined; they have been characterized as B 23, C 23 ( ref. $^{7}$ ) and RNA polymerase $1\left(\right.$ ref. $\left.^{6}\right)$ and are attributed to acidic, non-histone constituents ${ }^{7}$.
According to studies, increased expression of NOR sites is expected in actively proliferating cells and they are visualized in those cells which are functionally active in the preceding interphase. Counting AgNORs in interphase nucleus may assist in diagnosing and grading malignant neoplastic lesions ${ }^{8,9}$. Moreover, malignant cells have larger AgNOR than benign cells ${ }^{10}$. The increased AgNOR size could be attributed to increased transcriptionally active ribosomal sites. Malignant cells are characterized by small size, larger number and scattered distribution of AgNORs (ref. ${ }^{11}$ ). AgNOR silver staining technique enables the distinction to be made between certain grades of malignancy and may enable prognostic assessment ${ }^{12}$. AgNOR technique, with its cost-effectiveness and easily reproducible results, can be very effective in resourcepoor settings.

The endeavor of this study was to carry out a quantitative assessment of large and small AgNORs in specimens of oral normal mucosa, precancerous mucosal lesions and infiltrating squamous cell carcinomas previously diagnosed on $\mathrm{H} \& \mathrm{E}$ stain. 


\section{MATERIAL AND METHODS}

30 samples with dysplastic lesions of the oral cavity and 60 samples of well differentiated carcinomas were selected from the archives of Department of Oral Pathology \& Microbiology, Bharati Vidyapeeth Dental College \& Hospital, Pune, for which histopathological diagnosis and reporting had been done previously. As controls, 20 normal oral mucosa biopsies were taken from twenty consenting, healthy volunteers without any tobacco habit/ smoking. Samples were from different intra-oral sites i.e.buccal mucosa, alveolus, tongue, palate, retromolar area, vestibule and floor of mouth. 82 men and 28 women patients (age ranging from 21 to $75 \mathrm{yrs}$ ) participated in the study. Using hematoxylin-eosin (H\&E) stained sections, the cases were divided into the following three groups.

Group 1: normal oral mucosa $(n=20)$.

Group 2: mild, moderate and severe dysplasia, histopathologically graded by two oral pathologists evaluating independently (to avoid observer bias in the grading of dysplasia) based on established criteria by Pindborg and Smith 1997 (ref. $\left.^{13}\right)(n=30)$.
Group 3: histopathologicaly diagnosed well differentiated squamous cell carcinomas $(n=60)$.

Two sets of sections were cut from each block at a thickness of 3-4 $\mu$. One set of sections was stained by Ehrlich's Hematoxylin and Eosin for confirmation of the previous histopathologic diagnosis. All H\&E-based diagnoses were independently verified by two experienced oral pathologists. Cases with ambiguity in the histopathological doagnosis were excluded. Following this, the other set of sections was stained for the Argyrophilic Nucleolar Organizer regions by an improved method of Ploton et al 1986 (ref. ${ }^{4}$ ) and the AgNOR count was established for each specimen. The histopathological diagnosis of each specimen was then compared with the characteristics evident on AgNOR staining.

AgNOR staining and counting:

AgNOR staining was performed according to the procedure established by the Committee on AgNOR quantification ${ }^{14}$ incorporating recommended safeguards to reduce variability and bias in staining and counting ${ }^{15}$. Each section was immersed in sodium citrate buffer (at $\mathrm{pH} \mathrm{6.0)} \mathrm{incubated} \mathrm{in} \mathrm{wet} \mathrm{autoclave} \mathrm{at} 1208^{\circ} \mathrm{C}$ for $20 \mathrm{~min}$,

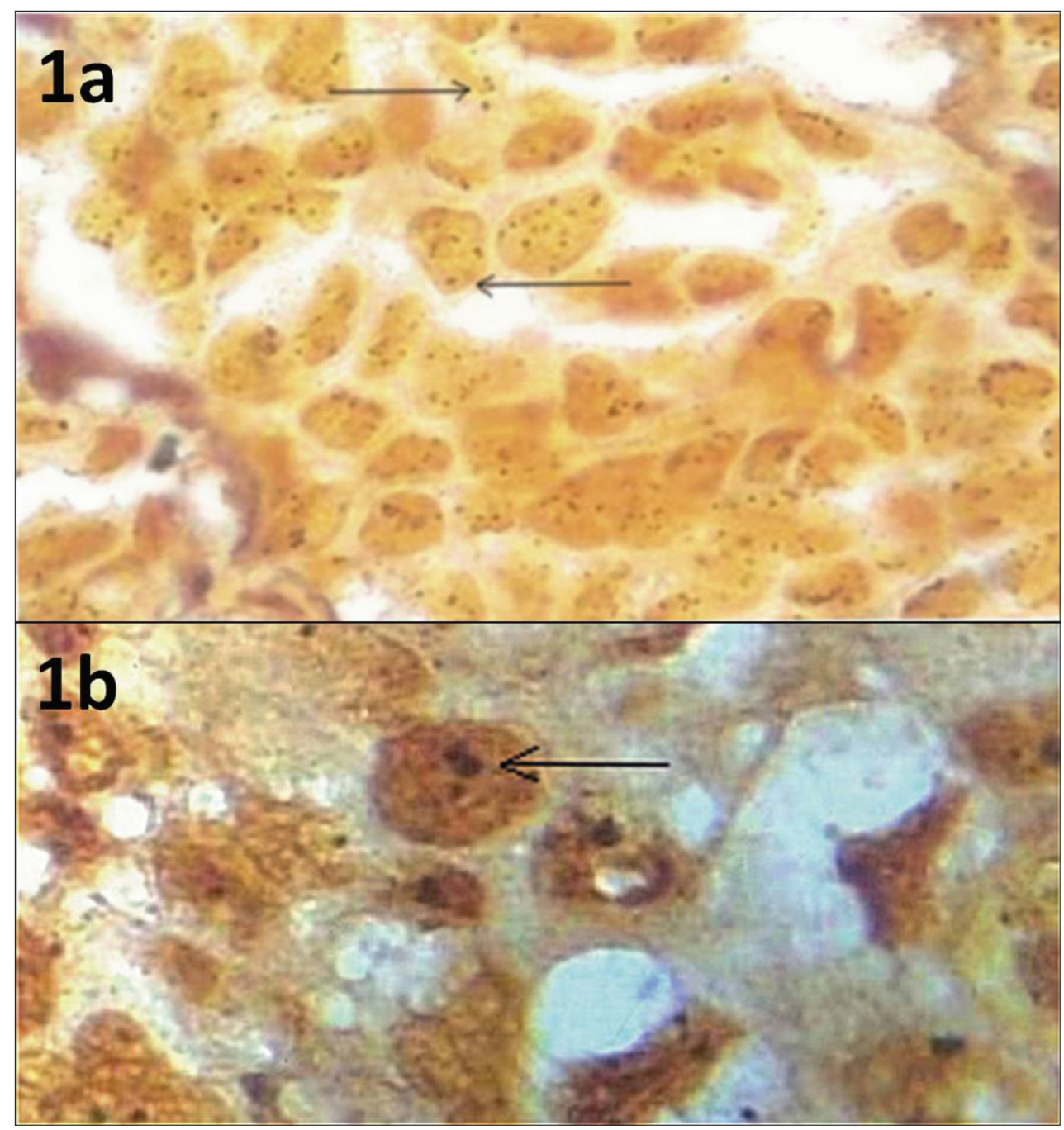

Fig. 1. Photomicrograph (a) showing Small AgNORs (100X; AgNOR stain), (b) showing Large AgNORs (100X; AgNOR stain). 
then allowed to cool down to $378{ }^{\circ} \mathrm{C}$. The slides were then immersed in a freshly prepared silver staining solution containing one part by volume of $2 \%$ gelatin in $1 \%$ formic acid, two parts of $25 \%$ aqueous silver nitrate solution at $378{ }^{\circ} \mathrm{C}$ in a thermostatically controlled environment for $11 \mathrm{~min}$. The slides were then washed with doubledistilled de-ionized water and the reaction was stopped. All stained sections were dehydrated in increasing grades of concentration of ethanol, and then clarified in xylene. All AgNOR quantification was performed by one of the authors.

Quantitative analysis: All stained sections were examined under oil immersion (100X) objective lens. In each of the sections, 100 individual cells were examined for methodical and systematic quantification of AgNORs, using a 100X oil immersion objective and 10X eye piece giving a total magnification of 1000X. Fields were selected at random and 100 cells were examined continuously. Each nucleus was examined for number of nucleoli. A nucleolus was defined as an AgNOR dot and the mean number of AgNOR was calculated.

In all sections, the argyrophilic, NORs were clearly evident as black "dots" or "blebs" of varying size, in the brown stained nucleus on a pale yellow background. The overall slide background was clear without any extraneous silver deposits. The black dots, which were visible in each cell, were evaluated depending upon the size into "large" NORs $(>=2 \mathrm{~m})$ and "small" NORs $(<2 \mathrm{~m})$. No counterstain was used to avoid obscuring the NOR dots. The AgNORs were counted as per the standardized guidelines recommended by Crocker et $\mathrm{al}^{12}$. When AgNORs were seen in groups, each cluster was counted as one AgNOR. When AgNORs could be seen separately but large enough to occupy a substantial area, it was counted as one "large" NOR, and the smaller NORs which were distinctly visible, were counted as one "small" NOR.

AgNORs were counted in each nucleus and categorized as large NORs which appeared as blebs and small NORs which appeared as distinct small dots. Further, the total number of AgNORs in each cell was calculated by summing both counts and was initially recorded in a separate table. From these values the means of large, small and total AgNORs were obtained and tabulated.

Statistical analysis was performed using SPSS software version 14.0 (Statistical Package for Social Sciences). The results processed using unpaired students " $\mathrm{t}$ " tests. Values for $P$ less than 0.05 were regarded as significant.

\section{RESULTS}

The maximum number of squamous cell carcinomas was in males and the most common site being the buccal mucosa.

NORs were strictly located within the cell nucleus and were distinctly stained in black as dots and blebs that were

Table 1. Mean values of small, large and total AgNOR counts in Normal, Dysplasia and carcinoma patients.

\begin{tabular}{|c|c|c|c|c|c|c|}
\hline \multicolumn{7}{|c|}{ Small AgNOR counts } \\
\hline Samples & $\begin{array}{c}\text { Number of } \\
\text { patients }\end{array}$ & Min & Max & Mean & S.D & $P$ value \\
\hline Normal & 20 & 0.33 & 1.93 & 1.17 & 0.58 & $<0.001$ \\
\hline vs Dysplasia & 30 & 1.53 & 2.64 & 2.05 & 0.33 & \\
\hline Normal & 20 & 0.33 & 1.93 & 1.17 & 0.58 & $<0.001$ \\
\hline vs Carcinoma & 60 & 1.92 & 4.50 & 3.247 & 0.73 & \\
\hline Dysplasia & 30 & 1.53 & 2.64 & 2.05 & 0.33 & $<0.001$ \\
\hline vs Carcinoma & 60 & 1.92 & 4.50 & 3.25 & 0.73 & \\
\hline \multicolumn{7}{|c|}{ Large AgNOR counts } \\
\hline Normal & 20 & 0.22 & 1.87 & 0.78 & 0.57 & $<0.001$ \\
\hline vs Dysplasia & 30 & 1.19 & 2.46 & 1.71 & 0.39 & \\
\hline Normal & 20 & 0.22 & 1.87 & 0.78 & 0.57 & $<0.05$ \\
\hline vs Carcinoma & 60 & 1.12 & 2.98 & 1.94 & 0.50 & \\
\hline Dysplasia & 30 & 1.19 & 2.46 & 1.71 & 0.39 & $>0.001$ \\
\hline vs Carcinoma & 60 & 1.12 & 2.98 & 1.94 & 0.50 & \\
\hline \multicolumn{7}{|c|}{ Total AgNOR counts } \\
\hline Normal & 20 & 0.62 & 3.67 & 1.95 & 1.04 & $<0.001$ \\
\hline vs Dysplasia & 30 & 2.98 & 4.64 & 3.76 & 0.57 & \\
\hline Normal & 20 & 0.62 & 3.67 & 1.95 & 1.04 & $<0.001$ \\
\hline vs Carcinoma & 60 & 3.48 & 6.77 & 5.19 & 0.90 & \\
\hline Dysplasia & 30 & 2.98 & 4.64 & 3.76 & 0.57 & $<0.001$ \\
\hline vs Carcinoma & 60 & 3.48 & 6.77 & 5.19 & 0.90 & \\
\hline
\end{tabular}

$\mathrm{N}$ - number of patients, Min- minimum value, Max- maximum value, S.D.- Standard deviation 
either round or elongated: the rest of the nucleus stained yellow-brown. The mean number of small NORs (Fig. 1a), large NORs (Fig. 1b) and total AgNORs, calculated for normal, dysplastic and squamous cell carcinoma cases is shown in Table 1.

In all categories of specimen, both small and large AgNORs were most common in the basal layers and became progressively less frequent in the superficial layers.

As observed throughout, there was an increase in number of small AgNORs in squamous cell carcinomas (mean 3.25) compared to that of dysplastic lesions (mean 2.05) and normal mucosa (mean 1.17) (Table 1, Fig. 2). The large AgNORs were increased in dysplastic lesions (1.71) and squamous cell carcinomas (1.94) as compared to normal mucosa (0.78) but the difference is not as remarkable as seen with the small AgNORs.

\section{STATISTICAL SIGNIFICANCE OF AgNORs}

In comparison to normal mucosa, a highly significant increase in small, large and total AgNORs was seen in dysplastic lesions and squamous cell carcinomas $(P<0.05)$ Squamous cell carcinomas also showed a significantly higher frequency of AgNOR than dysplasia. Comparing large AgNORs in dysplastic lesions and squamous cell carcinomas, a nonsignificant increase in the mean values was noticed in squamous cell carcinomas. When mean values of total AgNORs were tallied between dysplastic lesions and squamous cell carcinomas, a highly significant $(P<0.05)$ increase was found in squamous cell carcinomas (Table 1).

Of the different sites of occurrence, except for the palate, the mean frequency of large AgNORs in squamous cell carcinomas was statistically higher than in normal mucosa $(P<0.05)$. However, the mean values for small and the total AgNOR counts showed a highly significant increase irrespective of its site of occurrence $(P<0.05)$.

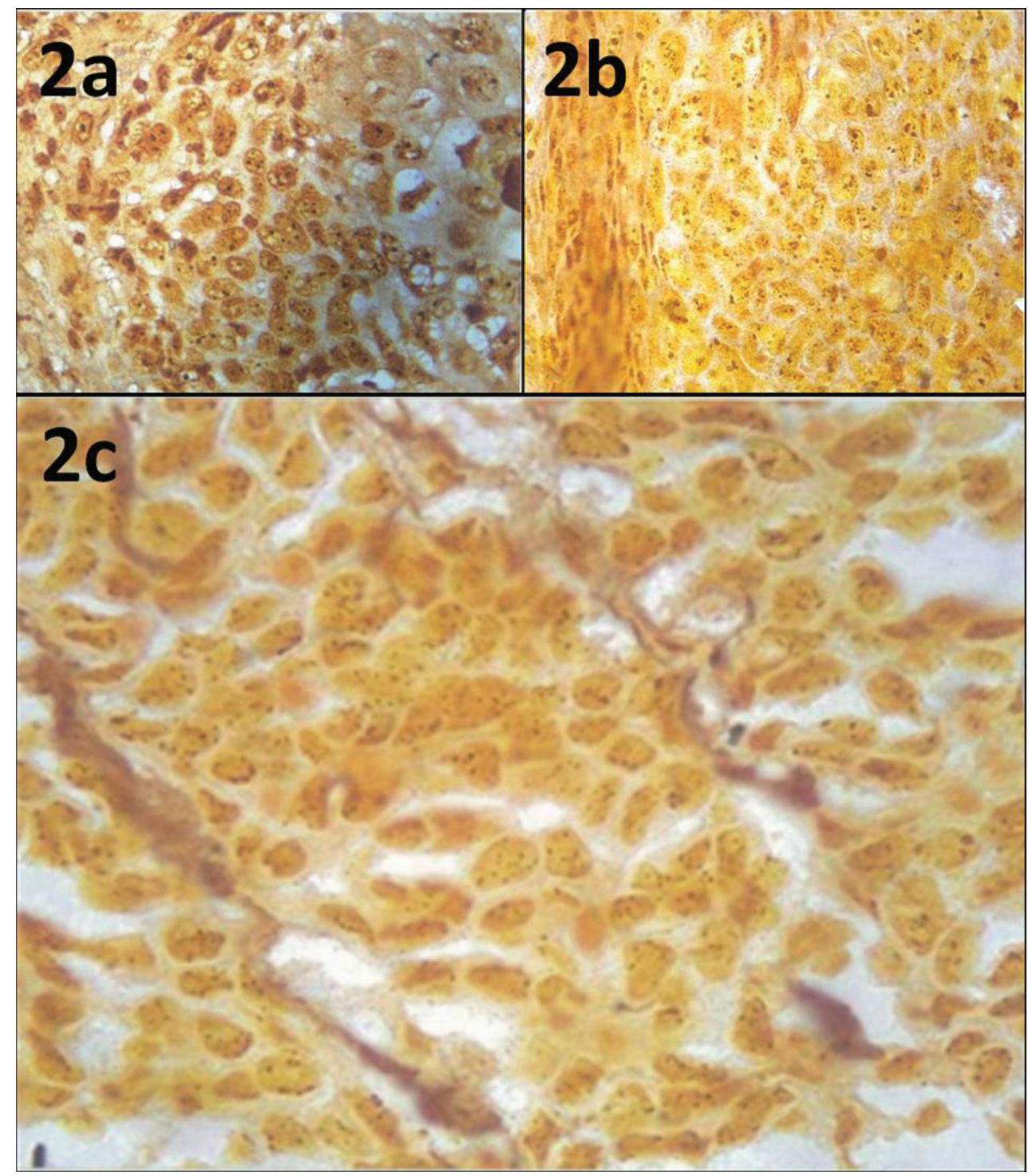

Fig. 2. Photomicrograph of (a) Normal Mucosa showing AgNOR staining (100X; AgNOR stain), (b) Dysplastic Mucosa showing AgNOR staining (100X; AgNOR stain), (c) Carcinomatous Mucosa showing AgNOR staining (100X; AgNOR stain). 


\section{DISCUSSION}

The nucleolar organizer regions (NORs) have been recognized for over a decade as loops of rDNA, which transcribe to rRNA. The most commonly used method for staining the NORs in vogue today is the AgNOR staining method, which identifies NOR associated proteins (NORAPs) whose function in unclear. The AgNOR technique helped cytogeneticists with a simple tool for the study of these structures in tumor pathology $y^{5,6,16}$. Quantitative estimation of interphase AgNORs is useful for evaluation of cell kinetics. Protein synthesis is faster in rapidly dividing cells. Accumulation of interphase AgNORs during the mitotic cycle is correlated with the increased demand for ribosomal biogenesis. Accordingly, an increase in the nucleolar structures (AgNORs), where rRNA synthesis takes place, is expected in rapidly diving cells. The AgNOR parameter is thus a convenient marker for studying the rate of proliferation of cells in tissues being studied histologically.

Hence, in the present study this technique was followed for its convenience and feasibility. We studied a range of oral epithelial lesions which are commonly encountered in the natural history of oral carcinoma in order to examine whether these lesions share common or dissimilar features in relation to AgNOR patterns and numbers. The present study also evaluated the significance of the frequency of small, large and total AgNORs. To the best of our knowledge, ours is the first study assessing the size of AgNORs and using it as criteria for distinguishing normal mucosa, oral dysplasia and oral squamous cell carcinoma.

In the present study, the frequency of small, large and total AgNORs increased with malignant progression from normal mucosa to squamous cell carcinomas of the oral cavity $((\mathrm{P}<0.05)$; Table I $)$, in agreement with earlier report $^{17-19}$. This clearly indicates that the total AgNOR counts increase with the changes occurring in the normal epithelium towards a dysplastic change and its malignant transformation. Interestingly, increase in AgNORs counts is associated with a concomitant increase in biochemically assayed DNA in the affected cell. In human cells, the degree of argyrophilia of individual NORs on chromosomes is constant and inheritable. The size of silver stained NORs is also related to the degree of transcriptional activity of the rDNA concerned. Thus larger AgNOR sites on chromosomes are more numerous in transcriptionally active cells than those of smaller size. But this may not be true in interphase nuclei in malignant cells ${ }^{20}$.

The small AgNORs were more frequent in cancerous mucosa at all sites, whereas, the large AgNORs showed no significant increase in carcinoma of the palate. Although, this could be artifactual due to small sample size, quantification of small AgNORs might have a greater discriminate value for distinguishing dysplasia and carcinoma.

Even though the reason for the greater number of AgNORs in the nuclei of malignant lesions is uncertain, it may represent an escalation in ploidy ${ }^{19}$, increased gene amplification or a rise in chromosomal segregation with more cells being in the $\mathrm{S}$ phase of their cycle ${ }^{21}$. In agree- ment with Derenzini et al. ${ }^{14}$, we also found an inverse correlation between malignant change and the size of AgNORs. Although AgNORs became more numerous with malignant progression from dysplastic lesions to frank carcinoma, their sizes became smaller. This may well represent increased transcriptional activity resulting in more rRNA gene copies with increasing proliferative activity.

\section{CONCLUSION}

Combining enumeration of AgNORs and size, we were able to reliably distinguish between normal, dysplastic and infiltrating squamous cell carcinomas. This could help in the early diagnosis of dysplastic mucosal lesions and their malignant transformation. It may also be applicable in the prognosis of prophylactically treated premalignant lesions and in treatment planning.

\section{CONFLICT OF INTEREST STATEMENT}

The authors state that there are no conflicts of interest regarding the publication of this article.

\section{REFERENCES}

1. Sthal A. The nucleolus. Jordan EG, Cullis CA. Press Syndicate of the University of Cambridge; 1982

2. Underwood J, Giri D. Nucleolar organizer regions as diagnostic discriminants for malignancy. J Pathol 1988;155:95.

3. Pandit S, Aithal D. A qualitative and quantitative estimation of AgNORS in dysplastic and non-dysplastic leukoplakias. Indian J Dent Res 2002;13:27.

4. Iwata H, Otoshi T, Takada N, Murai T, Tamano S, Watanabe T, et al. Validation of silver-stained nucleolar organizer regions for evaluation of invasive character of urinary bladder carcinoma in rats and mice. Urol Res 1995;23:27.

5. Papadopoulos N, Simopoulos C, Hatzimichael A, Kotini A, Tamiolakis D. Nucleolar organizer regions (NORs). Their significance in the determination of the origin of the lymphoid vessels. Panminerva Med 2003;45:63.

6. Mukhopadhyay S. Quantitative estimation of AgNORs in inflammatory gingival overgrowth in pediatric patients and its correlation with the dental plaque status. J Indian Soc Pedod Prev Dent 2009;27:235.

7. Paweletz N, Risueño MC. Transmission electron microscopic studies on the mitotic cycle of nucleolar proteins impregnated with silver. Chromosoma 1982;85:261.

8. Murray PG, Boldy DA, Crocker J, Ayres JG. Sequential demonstration of antigens and AgNORs in frozen and paraffin sections. J Pathol 1989;159:169.

9. Williams MA, Kleinschmidt JA, Krohne G, Franke WW. Argyrophilic nuclear and nucleolar proteins of Xenopus laevis oocytes identified by gel electrophoresis. Exp Cell Res 1982;137:341.

10. Lim SM, Duggan MA, Ruff M, Rahim S, McGregor SE, Green FH. Morphometric analysis of nucleolar organizer regions in benign and malignant peritoneal effusions using backscattered electron microscopy. J Pathol 1992;166:53.

11. Yang $P$, Huang GS, Zhu XS. Role of nucleolar organiser regions in differentiating malignant from benign tumours of the colon. J Clin Pathol 1990;43:235.

12. Crocker J, Boldy DA, Egan MJ. How should we count AgNORS? Proposals for a standardized approach. J Pathol 1989;158:185. 
13. Fakan $S$, Hernandez-Verdun D. The nucleolus and the nucleolar organizer regions. Biol Cell 1986;56:189.

14. Derenzini M, Betts CM, Eusebi V. Distribution of interphase nucleolar organiser regions and diagnosis of malignancy. Lancet 1987;2:286.

15. Bukhari MH, Niazi S, Khaleel ME, Sharif MA, Ghani R, Mehmood MT, et al. Elevated frequency of $\mathrm{p} 53$ genetic mutations and AgNOR values in squamous cell carcinoma. J Cutan Pathol 2009;36:220.

16. Warnakulasuriya KA, Johnson NW. Nucleolar organiser region (NOR) distribution as a diagnostic marker in oral keratosis, dysplasia and squamous cell carcinoma. J Oral Pathol Med 1993:22:77.

17. Teresa DB, Neves KA, Neto CB, Fregonezi PAG, De Oliveira MRB, Zuanon JAS, et al. Computer-assisted analysis of cell proliferation markers in oral lesions. Acta Histochem 2007;109:377.
18. Moradzadeh Khiavi M, Vosoughhosseini S, Halimi M, Mahmoudi SM, Yarahmadi A. Nucleolar organizer regions in oral squamous cell carcinoma. J Dent Res Dent Clin Dent Prospect 2012;6:17.

19. Hanemann JAC, Miyazawa M, Souza MSG dos S. Histologic grading and nucleolar organizer regions in oral squamous cell carcinomas. J Appl Oral Sci 2011;19:280.

20. Egan M, Freeth M, Crocker J. Intraepithelial neoplasia, human papilloma virus infection and argyrophilic nucleoprotein in cervical epithelium. Histopathology 1988;13:561.

21. Crocker J, Egan MJ. Correlation between NOR sizes and numbers in non-Hodgkin's lymphomas. J Pathol 1988;156:233. 